\title{
FOR HIGH TEMPERATURES
}

Frustrated by columbium's poor oxidation resistance, metallurgists are devoting considerable research effort to provide this metal with a self-healing coating. Here is one answer arrived at by the U.S. Naval Research Laboratory.

Fig. 1-Intermetallic layers on $\mathrm{Cb}$ wire dipped in molten $\mathrm{Zn}$ at $1025^{\circ} \mathrm{F}$ and then diffusion-annealed in air at $1600^{\circ} \mathrm{F}$ for $16 \mathrm{hr}$. $\mathrm{X500}$, reduced to 45 pet.

\section{by G. Sandoz}

$C$ OLUMBIUM has all the essentials for a good base-metal for the development of superior high-temperature alloys except for its poor oxidation resistance. Alloy additions confer some oxidation resistance, but only at the expense of high-temperature strength or of fabricability or both. It appears that unless and until some useful oxidationresistant alloys are proved out, a parallel effort must be made to develop coatings for those alloys which are strong and fabricable.

In addition to providing protection against oxidation, a useful coating must also have the quality of repairing (over the temperature range to be experienced by the coated object) any cracks or flaws initially present in the coating or which might be expected to form because of mechanical or thermal strain in service. The U. S. Naval Research Laboratory has developed a type coating to meet these two requirements.

In its simplest form, this new coating consists of layers of intermetallic zinc-columbium compounds on the surface of the columbium. The intermetallics may be formed by applying zinc in any of several ways, the simplest of which is perhaps by dipping the columbium in molten zinc. Subsequently, the zinc is reacted with the columbium substrate in a diffusion-anneal in air in the general range of $1600^{\circ} \mathrm{F}$, a treatment which also causes layers of zinc oxide and zinc-columbium oxide to form on the surface. Fig. 1 shows the intermetallic layers of the coated and diffused columbium.

As with most intermetallic compounds, the zinccolumbium intermediate phases are hard and brittle, and they are readily cracked either by mechanical strain or by thermal shock, but they are securely anchored to the columbium substrate and do not tend to spall, and in fact can be dislodged only with great difficulty.

Such a coating produced from unalloyed zinc and unalloyed columbium protects against influx of oxygen (as judged by microhardness traverses and bend-ductility) for several hundreds of hours at $1800^{\circ} \mathrm{F}$ and for a few days to a few hours in the range $2000^{\circ}$ to $2200^{\circ} \mathrm{F}$ in still air.

Preliminary evaluation in hydrocarbon combustion products moving at $500 \mathrm{ft}$ per sec and with metal temperature of $2000^{\circ} \mathrm{F}$ showed no indication of oxygen absorption or other embrittlement in tests of 5-hr duration. (Uncoated control specimens are completely converted to oxide in about $3 \mathrm{hr}$ at these temperatures.) The coating thus meets the first requirement-protection against oxidation.

Perhaps the most strikingly successful aspect of the zinc-type coating is its self-healing ability. An opening in the coating to bare columbium is rapidly covered by a thin layer of oxides; zinc coming from the adjacent coating quickly re-forms the intermetallic layers. One demonstration of this capability consisted of coating and diffusing a tab of columbium $1 / 2 \times 3 / 4 \times 0.063$ in., and then cutting a groove $1 / 4-$ in. wide through the coating and across the sample, thus exposing a bare columbium area approximately $1 / 4 \times 1 / 2$ in.; the flawed sample was then placed in a furnace at $1800^{\circ} \mathrm{F}$ for $20 \mathrm{hr}$. After the tab was removed, it appeared as in Fig. 2. A section through the flawed zone showed a moderate increase in hardness near the flaw (original: VPN 100; final: VPN 130), suggesting a small influx of oxygen during the initial stages of healing. Fig. 3 shows the intermetallic layer re-formed at the bare area from the adjacent zinc intermetallic reservoir. Some of the consequences of this self-healing capability are that stress-rupture specimens are protected during extension, and structures do not oxidize when they are damaged while exposed to high temperatures.

It is intended to publish, at a later date, details of studies on the effects of third and fourth elements and other processing variables on the capabilities of this type of coating, as well as studies on the crystallography and fundamental physical metallurgy involved.

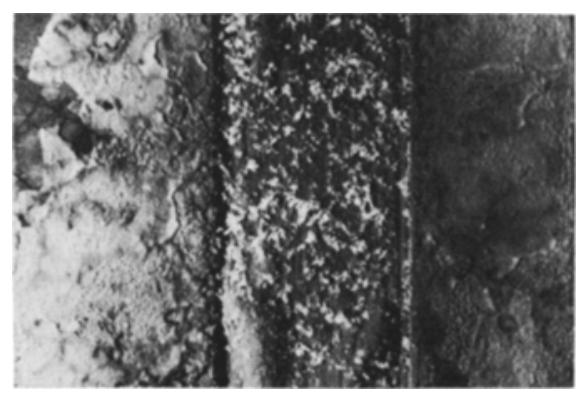

Fig. 2 (left) -A $1 / 4 \times 1 / 2$-in. flaw on a coated $\mathrm{Cb}$ tab after reheating to $1800^{\circ} \mathrm{F}$ in air for 20 hr. $X 3$.

Fig. 3 (right)-The intermetallic layer reformed at the surface of the $1 / 4 \times 1 / 2$-in. flaw on the coated $\mathrm{Cb}$ tab. X1000, reduced to 75 pct.

G. SANDOZ is with the Metallurgy div of the U.S. Naval Research Laboratory, Washington, D. C.

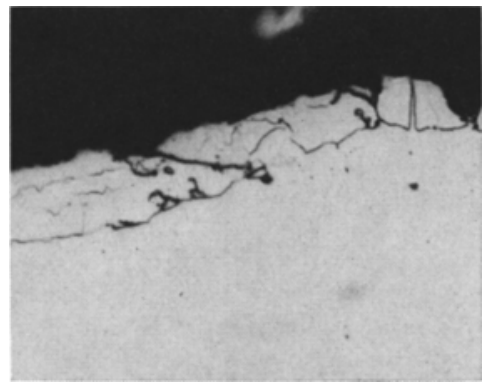

